Artigo Original

Original Article

Carolina Lisbôa Mezzomo ${ }^{1}$

Simone Weide Luiz ${ }^{2}$

Descritores

Pré-escolar

Fala

Fonética

Desenvolvimento infantil

Desenvolvimento da linguagem

Keywords

Child, preschool

Speech

Phonetics

Child development

Language development
Endereço para correspondência: Simone Weide Luiz

R. Francisco Manuel, 360/202, Santa Maria (RS), Brasil, CEP: 97015-070.

E-mail: simonewluiz@hotmail.com

Recebido em: 8/9/2011

Aceito em: 12/3/2012

\section{Interferência da variante linguística nas estratégias de reparo utilizadas no processo de aquisição fonológica}

\author{
Interference of the linguistic variant in the repair strategies \\ used during the phonological acquisition process
}

\section{RESUMO}

Objetivo: Investigar e comparar o uso de estratégias de reparo na aquisição do /R/ em onset simples empregadas por crianças com aquisição fonológica típica. Métodos: Foram utilizados dados de fala contendo o 'r-forte' de 120 crianças com aquisição fonológica típica, sendo 60 do gênero feminino e 60 do gênero masculino, residentes de Santa Maria (RS) e de Crissiumal (RS), com idades entre 1 ano e 6 meses e 4 anos. Para a análise das estratégias de reparo empregadas foram consideradas as variáveis dependentes omissão, substituição por j e w, e substituição por [1] e/ou [r], e as variáveis independentes gênero, idade, contexto precedente e seguinte, classe gramatical, tonicidade, número de sílabas e posição na palavra. Os dados foram codificados e submetidos à análise estatística por meio do programa VARBRUL. Resultados: O programa estatístico selecionou como significativos na rodada da omissão em Santa Maria tonicidade e gênero e em Crissiumal tonicidade e faixa etária. Na rodada da substituição por j e w em Santa Maria o programa selecionou gênero e em Crissiumal tonicidade. Na rodada da substituição pelo [1] em Santa Maria nenhuma variável foi selecionada e em Crissiumal as variáveis posição na palavra, gênero e faixa etária foram selecionadas. Conclusão: Foi possível observar que as estratégias de reparo podem divergir conforme a variante utilizada. Deve-se, portanto, considerar a variação dialetal para que a terapia fonológica seja mais eficiente.

\begin{abstract}
Purpose: To investigate and compare the use of repair strategies in the acquisition of /R/ in simple onset, produced by children with typical phonological acquisition. Methods: Speech data containing the /R/ from 120 children with typical phonological acquisition (60 male and 60 female) from Santa Maria (RS) and Crissiumal (RS), Brazil, aged between 1 year and 6 months and 4 years were used. To analyze the repair strategies, the following dependent variables were considered: omission, semivocalization, and liquid substitution; as well as the following independent variables: gender, age, precedent and following context, grammatical class, tonicity, number of syllables, and position in the word. The VARBRUL program was used for statistical analysis. Results: The statistical program selected as significant for omission in Santa Maria the variables tonicity and gender, and in Crissiumal, tonicity and age. For semivocalization in Santa Maria, the program selected the variable gender, and in Crissiumal, tonicity. For lateral liquid substitution in Santa Maria the statistical program did not select any variable. However, in Crissiumal, the variables position in the word, gender, and age were selected. Conclusion: It was possible to observe that the repair strategies can diverge according to the dialect being used. Hence, it is important to consider the dialectal variation to make the phonological therapy more effective.
\end{abstract}

Trabalho realizado no Programa de Pós-Graduação em Distúrbios da Comunicação Humana, Universidade Federal de Santa Maria - UFSM - Santa Maria (RS), Brasil.

(1) Curso de Fonoaudiologia, Universidade Federal de Santa Maria - UFSM - SantaMaria (RS), Brasil.

(2) Programa de Pós-Graduação (Mestrado) em Distúrbios da Comunicação Humana, Universidade Federal de Santa Maria - UFSM - SantaMaria (RS), Brasil.

Conflito de interesses: Não 


\section{INTRODUÇÃO}

De modo geral, o domínio fonológico típico ocorre por volta dos cinco anos. As consoantes líquidas são as que possuem o domínio mais tardio ${ }^{(1)}$. Isso se dá porque elas são uma classe de sons bastante complexa, tanto do ponto de vista acústico-articulatório, quanto do ponto de vista fonológico ${ }^{(2)}$. Portanto, a classe das líquidas do Português Brasileiro, que são $/ 1 /, / K /$, /R/ e /r/, também sofre maior número de estratégias de reparo.

Durante a aquisição fonológica, as produções iniciais das crianças não são iguais ao padrão de fala adulto. No entanto, elas também não são desordenadas e caóticas. As tentativas de produção de fala, inicialmente, contêm características que demonstram quais as estratégias que as crianças estão utilizando para produzir determinados sons, quais as dificuldades encontradas e qual o nível de consciência fonológica. Essas tentativas de produção utilizadas não são assistemáticas e podem mostrar a presença de um subsistema fonológico e, por conseguinte, um conhecimento em construção ${ }^{(4)}$. No decorrer da aquisição fonológica ocorrem estratégias de reparo que devem desaparecer ao longo do tempo, sendo esperados determinados processos para cada faixa etária ${ }^{(2)}$. Em relação aos tipos de estratégias de reparo que ocorrem na aquisição do 'r-forte', um estudo mostra que podem ocorrer substituições por consoantes plosivas, substituições por líquida lateral e semivocalizações ${ }^{(5,6)}$.

Considerou-se, neste estudo, que as estratégias de reparo podem ser distintas, de acordo com a variante linguística que está sendo utilizada. Segundo um estudo(7), a variabilidade fonética é uma parte integrante do sistema linguístico e pode ou não levar à mudança linguística. As variantes linguísticas podem disputar espaço umas com as outras ao representar um dado fonema; nesse caso, há uma mudança em progresso. Mas a variação pode também apresentar características contínuas, sem haver declínio ou aumento de uma forma linguística sobre a outra. Observa-se, assim, uma variação estável.

Percebe-se que, pelo fato de no Rio Grande do Sul existir mais de uma variante para o 'r-forte', com diferentes características fonéticas e articulatórias, estas devem ser analisadas no momento de avaliar casos de desvio fonológico, para que as práticas terapêuticas sejam mais eficazes. Além disso, pelo fato de as variantes utilizadas nos dois municípios não serem as mesmas, espera-se que as estratégias de reparo empregadas pelas crianças também não sejam as mesmas.

Portanto, este estudo teve como objetivo investigar e comparar o uso das estratégias de reparo na aquisição da líquida não lateral /R/ em posição de onset simples empregadas por crianças com aquisição fonológica típica, residentes nos municípios de Crissiumal (RS) e de Santa Maria (RS). Decidiu-se investigar a aquisição do /R/ em onset simples, pois nesta posição ele apresenta variações, tanto individuais como dialetais. $\mathrm{O}$ ' $\mathrm{r}$ -forte' pode se superficializar como fricativa velar ou glotal (Santa Maria) e vibrante múltipla ${ }^{(3)}$ ou simples (Crissiumal). Como em onset simples os segmentos 'r-forte' e 'r-fraco' apresentam a característica de distintividade fonológica ${ }^{(2)}, \mathrm{o}$ uso da vibrante simples no lugar do 'r-forte' pode gerar uma perda desta distintividade em alguns dialetos.

\section{MÉTODOS}

Foram utilizados dados de fala de 120 crianças com aquisição fonológica típica, sendo 60 crianças residentes do município de Santa Maria (RS) e 60 crianças residentes do município de Crissiumal (RS). Estas crianças foram equiparadas em ralação à variável gênero, isto é, em cada município contou-se com 30 meninos e 30 meninas, todos falantes monolíngues do Português Brasileiro. A idade dos grupos variou de 1 ano e 6 meses a 4 anos. As faixas etárias foram divididas de dois em dois meses, com um total de 15 faixas por município. Em cada faixa, foram utilizados dados de fala de dois meninos e duas meninas.

As amostras de fala dos municípios de Santa Maria e de Crissiumal fazem parte de dois bancos de dados criados a partir da realização de projetos de pesquisa, aprovados pelo Comitê de Ética e Pesquisa da Universidade Federal de Santa Maria (UFSM), sob os números 064/2004 e 23081.011800/2010-89.

Em ambos os municípios os pais e/ou responsáveis pelas crianças que fizeram parte dos bancos de dados foram devidamente esclarecidos sobre os objetivos e procedimentos da pesquisa, autorizando a participação das mesmas por meio do Termo de Consentimento Livre e Esclarecido.

Em ambos os municípios foi realizada uma triagem fonoaudiológica para atentar se as crianças que fizeram parte do banco de dados e do estudo tinham desenvolvimento comunicativo típico. Além disso, elas não poderiam apresentar comprometimento evidente nos aspectos neurológicos, cognitivos ou psicológicos.

Para a formação dos bancos de dados, foram coletadas transversalmente amostras de fala com base no instrumento Avaliação Fonológica da Criança - $\mathrm{AFC}^{(8)}$. Este instrumento proporciona a nomeação espontânea de 125 palavras, por meio de cinco desenhos temáticos. O AFC foi aplicado individualmente em cada uma das crianças, sendo os dados de fala registrados em um gravador digital. Posteriormente, os dados foram transcritos por meio de transcrição fonética ampla e revistos por mais dois julgadores com experiência em transcrição fonética, separadamente.

Em Crissiumal, cada criança foi avaliada individualmente pela pesquisadora, sendo que a coleta de dados constituiu-se de duas etapas. Na primeira etapa, foi realizada uma entrevista com os pais e professores a fim de identificar a variante utilizada, que representava o input da criança. Na segunda etapa, houve a coleta de dados de fala, seguindo o mesmo método descrito para o município de Santa Maria, ou seja, o uso do instrumento AFC. Também foi utilizada uma lista de 30 palavras com 'r-forte' em onset inicial e medial.

As palavras levantadas no banco de dados de Santa Maria (corpus de 259 palavras) e as palavras coletadas em Crissiumal (corpus de 388 palavras) contendo o 'r-forte' (ex.: rato, cachorro) foram categorizada conforme foram produzidas. Para tanto, foram consideradas variáveis dependentes e independentes, extralinguísticas e linguísticas.

Como variantes da variável dependente em Santa Maria foram consideradas as estratégias: omissão (carro - [ $\left.{ }^{\mathrm{k}} \mathrm{kaw}\right]$ ), substituição pelos glides [w] e [j] (carro - ['kaju] ou ['kawu]), 
substituição por [r] ou [1] (carro - ['karo] ou ['kalu]). Em Crissiumal foram consideradas as estratégias: omissão, substituição pelos glides [w] e [j] e substituição por [1]. A substituição pela líquida não-lateral [r] não pode ser considerada como uma estratégia de reparo em Crissiumal, mas sim, como produção correta, pois o dialeto regional prevê esta variante como forma de superficialização do 'r-forte'.

Para a análise das estratégias de reparo empregadas na aquisição do 'r-forte' em posição de onset simples foram consideradas as variáveis extralinguísticas gênero e idade; e as variantes linguísticas contexto precedente e seguinte, tonicidade, número de sílabas e posição na palavra.

Para uma análise eficiente da variável idade, foram analisadas 15 faixas etárias por município, em intervalos de dois meses, conforme citado anteriormente. Quanto à variável gênero, foi realizada a análise da fala de 30 meninas e de 30 meninos em cada município. Esse aspecto foi considerado pelo fato de já ter sido mencionado em outros estudos como sendo um fator que confere uma diferença na aquisição da linguagem ${ }^{(9,10)}$.

A tonicidade foi analisada por meio das variantes pré-tônica (ex.: ratinho), tônica (ex.: rato) e pós-tônica (ex.: carro), pois o tipo de onset analisado permite estas ocorrências. Dentro da variável número de sílabas foi possível analisar os onsets em itens lexicais monossílabos (ex.: rio), dissílabos (ex.: rato), trissílabos (ex.: carroça) e polissílabos (ex.: arrumando). Em relação à variante contexto precedente fizeram parte as vogais: dorsal /a/ (ex.: arroz), dorsal labial /o/, / / / e /u/ (ex.: cachorro, forra, burro), coronal /e/, / $\varepsilon /$ e / i/ (ex.: erro, berro, birra). As vogais em contexto seguinte observadas foram: dorsal /a/ (ex.: garrafa), dorsal labial /o/, / / e /u/ (ex.: cachorro, roda, rua), coronal /e/, /ع/ e / i/ (ex.: rei, régua, sorriso). No que se refere à posição na palavra, as palavras foram categorizadas como onset simples inicial (ex.: relógio) e onset simples medial (ex.: carro).

As produções realizadas pelas crianças foram classificadas e categorizadas de acordo com as variáveis e variantes previamente descritas. Essa categorização foi digitada em um formulário no programa Microsoft Office Access 2003, que serviu de entrada para o programa estatístico.

Para a realização da análise estatística contou-se com o uso do Pacote Computacional VARBRUL. Esse conjunto de programas é largamente utilizado em análises sociolinguísticas ${ }^{(11-13)}$. Entretanto, o programa já vem sendo usado com sucesso, desde a década de 90 , com dados de aquisição da linguagem ${ }^{(9,10,14)}$. Utilizou-se o pacote VARBRUL pelas características e objetivos do presente estudo e pelo fato de ele ser capaz de fornecer frequências, probabilidades e selecionar variáveis em que há diferença estatística. O programa faz a análise probabilística na forma binária. Isto significa que esse programa, por meio de cálculos estatísticos, atribui pesos relativos às variantes das variáveis independentes, com relação às duas variantes (produção correta e incorreta) do fenômeno linguístico em questão, representadas pela variável dependente. Deve-se enfatizar que o VARBRUL atribui valores de significância às variáveis linguísticas e extralinguísticas por meio da interação entre as mesmas (ex.: gênero versus idade; tonicidade versus número de sílabas). Dessa forma, ele não atribui valor de p às variantes contidas dentro de uma variável. Por exemplo, o VARBRUL não gera um valor de significância na comparação entre o gênero masculino e o feminino. Para essas variantes, são atribuídos pesos relativos, isto é, probabilidades de maior ou menor interferência das mesmas na produção do /R/ em onset simples.

Os pesos relativos ou probabilidades de ocorrência do /R/ em onset simples foram retirados da interação estatística contendo todas as variáveis selecionadas pelo programa. Valores de peso relativo abaixo de 0,50 foram considerados desfavorecedores, valores probabilísticos entre 0,50 a 0,59 foram considerados neutros e valores iguais ou acima de 0,60 , foram considerados favorecedores.

\section{RESULTADOS}

Foi possível observar diferenças em relação às estratégias de reparo utilizadas em Crissiumal e em Santa Maria. Em Santa Maria houve maior frequência de utilização da estratégia omissão, enquanto em Crissiumal a estratégia mais utilizada foi a substituição pela líquida lateral.

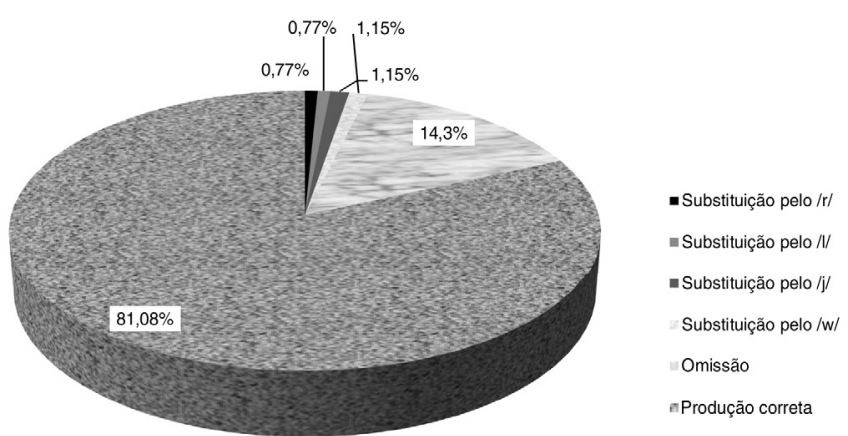

Figura 1. Ocorrência e uso de estratégias de reparo em Santa Maria

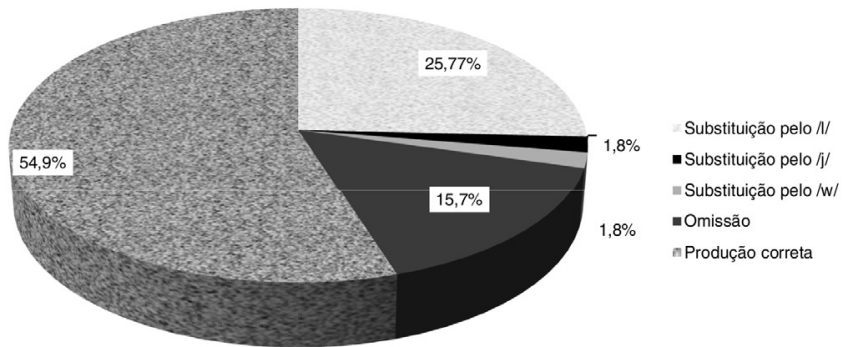

Figura 2. Ocorrência e uso de estratégias de reparo em Crissiumal

Na rodada da estratégia omissão, em Santa Maria, o programa estatístico selecionou as variáveis tonicidade (sílaba tônica) e gênero (masculino). Em Crissiumal foram selecionadas as variáveis tonicidade (pré-tônica) e faixa etária. Em Crissiumal, os maiores pesos relativos, que são favorecedores da omissão e as maiores frequências aparecem em faixas etárias alternadas (Tabela 1), enquanto em Santa Maria as maiores frequências pertencem às faixas intermediárias (Tabela 2).

Nas rodadas da estratégia substituição por [j] e [w], em Santa Maria, o programa estatístico selecionou o gênero masculino como favorecedor. Em Crissiumal, mesmo que não selecionado, o gênero masculino também apresentou maior 
frequência. Em Crissiumal, ainda em relação à substituição por [1] e [w], a variável tonicidade foi selecionada, sendo a variante pós-tônica (ex.: carro) favorecedora desta estratégia de reparo, o que concorda com a maior frequência observada em Santa Maria para tonicidade. No entanto, se considerarmos o número total de palavras, foram poucos os casos em que essa estratégia apareceu em ambos os municípios.

Em relação à estratégia substituição pelo [1], em Santa Maria apareceram apenas dois casos, por isso o programa estatístico não selecionou nenhuma variável para esta estratégia. Todavia, em Crissiumal, essa foi a estratégia de reparo mais empregada pelas crianças. Em Crissiumal, o programa estatístico

Tabela 1. Variáveis selecionadas em Santa Maria e em Crissiumal

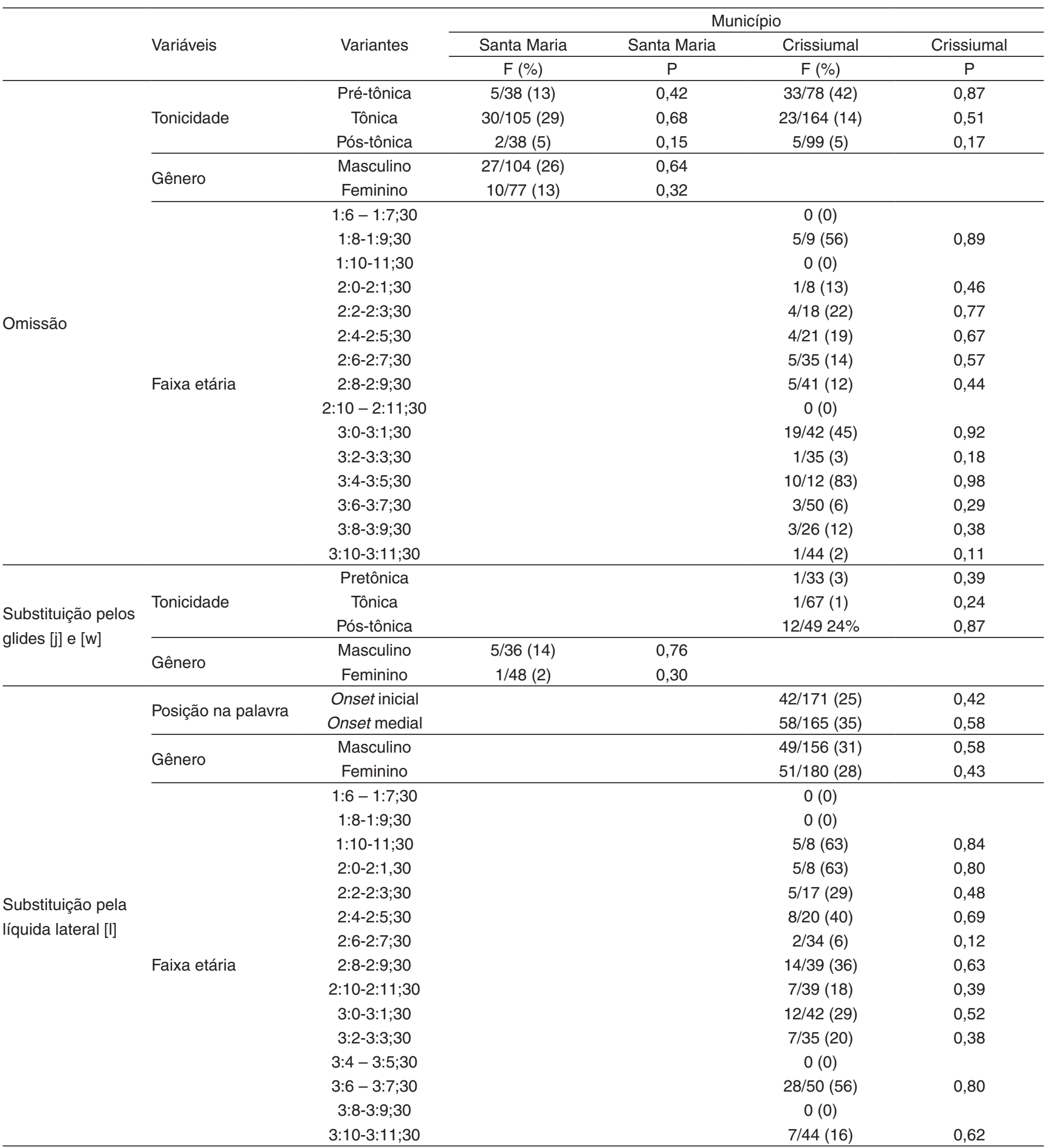


Tabela 2. Variáveis extralinguísticas não-selecionadas nas rodadas de Santa Maria e Crissiumal

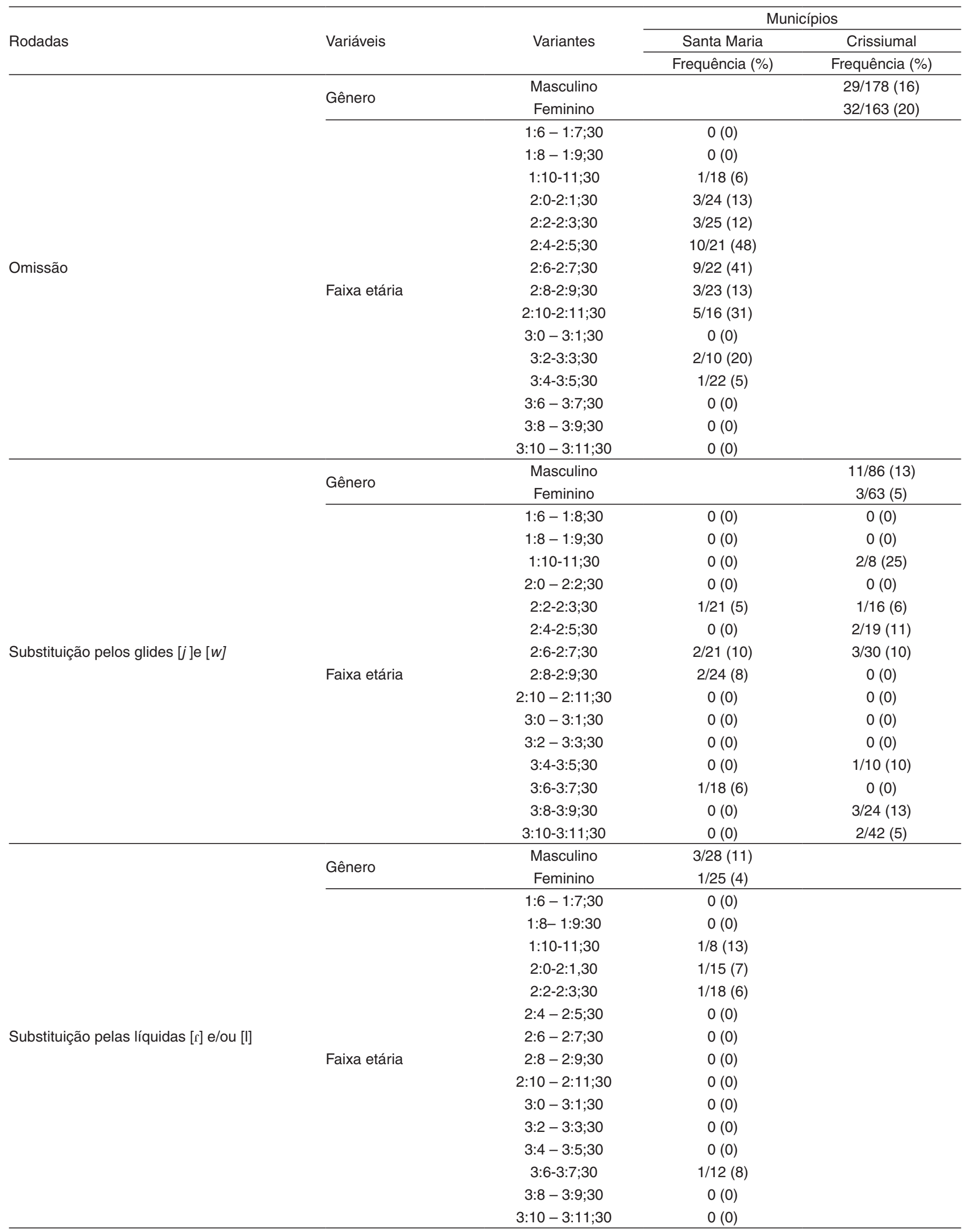

Pacote computacional VARBRUL $(p<0,05)$ 
selecionou, nesta rodada, posição na palavra, gênero e faixa etária. Em relação às variáveis posição na palavra e gênero, nenhuma variante foi favorecedora desta substituição, não atingindo valores de probabilidade iguais ou acima de 0,60. Contudo, as palavras em onset medial e o gênero masculino apresentaram as maiores frequências e pesos relativos. Quanto à faixa etária, as faixas que foram consideradas favorecedoras da substituição pelo [1] apareceram em faixas alternadas.

Em relação às variáveis extralinguísticas não selecionadas (Tabela 2) em Crissiumal, o gênero feminino apresentou maior frequência de omissão, apesar das frequências dos gêneros feminino e masculino estarem bastante próximas. Já em Santa Maria, como citado anteriormente, o gênero masculino foi o que apresentou maior frequência de omissão, com diferença em relação ao gênero feminino. A variável faixa etária não foi selecionada em Santa Maria na rodada da omissão, porém, como já citado, as maiores frequências apareceram nas faixas intermediárias.

Na rodada da substituição pelos glides [j] e [w], o programa estatístico não selecionou a variável gênero em Crissiumal, mas as maiores frequências foram em relação ao gênero masculino, concordando com os achados de Santa Maria. Em relação a esta mesma variável, a variante faixa etária não foi selecionada nem em Santa Maria e nem em Crissiumal. Todavia, em Santa Maria as maiores frequências apareceram em faixas intermediárias e em Crissiumal as maiores frequências estavam em faixas alternadas.

As variáveis gênero e faixa etária não foram selecionadas em Santa Maria na rodada da substituição pelas líquidas [r] e [1], que foram amalgamadas neste município, devido ao reduzido número de ocorrências. Contudo, o gênero masculino apresentou maior frequência e as crianças em faixas etárias iniciais tenderam a utilizar essa estratégia com mais frequência.

Em Crissiumal, foi realizada somente a rodada do programa estatístico considerando a variável substituição pelo [1]. Isso ocorreu porque, conforme já mencionado, o /R/ em onset simples produzido como vibrante simples é considerado produção correta neste município e as variáveis gênero e idade foram selecionadas pelo programa estatístico (Tabela 1).

Em relação às variáveis linguísticas não selecionadas (Tabela 3) em Santa Maria, observou-se que as frequências de omissão das variantes utilizadas ocorreram em maior frequência no contexto precedente vogal coronal (ex.: erro), enquanto em Crissiumal o contexto nulo apareceu com maior frequência. Em contexto seguinte, pôde-se observar as maiores frequências na variante coronal para ambos os municípios.

Ainda em relação à omissão, Santa Maria e Crissiumal apresentaram frequências bastante semelhantes em relação ao número de sílabas, com as maiores frequências em palavras trissílabas (ex.: cachorro). Apenas em palavras monossílabas (ex.: rio), em Santa Maria, não houve nenhum caso de omissão. As crianças residentes em Santa Maria omitiram o /R/ com frequências semelhantes tanto em onset inicial (ex.: rato), quanto em onset medial (ex.: carro), que possuiu uma frequência levemente maior. Já em Crissiumal, ocorreram mais casos de omissão em palavras com o /R/ em onset inicial.

A substituição pelos glides [j] e [w], conforme mencionado anteriormente, apareceu em poucos casos, em ambos os municípios. Porém, em Crissiumal a vogal labial/dorsal (ex.: cachorro) foi a que mais apareceu em contexto precedente. Em Santa Maria a substituição referida não ocorreu nesta variante. Em contexto seguinte, em Santa Maria, a vogal labial/dorsal (ex.: carro) foi a que mais apareceu. Em Crissiumal, não ocorreu a substituição pelos glides [j] e [w] em contexto seguinte. Tanto em Crissiumal quanto em Santa Maria, os glides [j] e[w] apareceram com maior frequência em sílabas pós-tônicas (ex.: carro) e não apareceram em palavras monossílabas (ex.: rio). Palavras com o $/ \mathrm{R} /$ em onset medial (ex.: carro) foram as palavras com as maiores frequências em ambos os municípios.

Em relação à substituição pelas líquidas [1] e [r], em Santa Maria, não ocorreram resultados significativos, devido ao reduzido número de ocorrências desta estratégia. No entanto, as palavras com vogal labial/dorsal em contexto precedente (ex.: cachorro) e em contexto seguinte (ex.: cachorro) foram as que apresentaram as maiores frequências, embora não selecionadas pelo programa estatístico. Em Crissiumal, pôde-se observar um elevado número de ocorrências em todas as vogais, tanto em contexto precedente quanto seguinte, com exceção do contexto precedente com vogal coronal (ex.: erro). A maior frequência em contexto precedente foi preenchida pela vogal dorsal (ex.: arroz) e, em contexto seguinte, pela vogal labial/ dorsal (ex.: carro). Em relação à tonicidade, em Santa Maria, as sílabas tônicas (ex.: rádio) foram as de maior frequência e em Crissiumal, as sílabas pós-tônicas (ex.: carro) apresentaram a maior frequência. Em Santa Maria e em Crissiumal as palavras polissílabas (ex.: arrumando) apresentaram as maiores frequências de substituição pelas líquidas [r] e/ou [1], contudo elas apareceram em pequena quantidade em ambos os municípios. Em Santa Maria, mesmo não selecionadas, as palavras com o [R] em onset medial (ex.: correndo) apareceram com maior frequência, da mesma forma que em Crissiumal, como anteriormente referido.

\section{DISCUSSÃO}

A partir dos resultados obtidos, pôde-se observar que as estratégias de reparo utilizadas em Santa Maria foram respectivamente omissão, substituição pelos glides [j] e [w] e substituição pelas líquidas [1] e [r]. Em Crissiumal, as estratégias de reparo empregadas apresentaram a seguinte ordem de frequência de ocorrência: substituição pela líquida lateral [1], omissão e substituição pelos glides [j] e [w]. Os achados concordam com um estudo, em que as estratégias de semivocalização de líquida e de substituição de líquida também ocorreram em diferentes estágios de aquisição das consoantes líquidas ${ }^{(15)}$. Há ainda outra pesquisa que percebeu que estratégias como omissões de segmentos e substituições são utilizadas pelas crianças durante a aquisição fonológica ${ }^{(16,17)}$.

Em Santa Maria, as variáveis selecionadas na rodada da omissão foram tonicidade e gênero, o que indicou que a sílaba tônica e o gênero masculino são favorecedores da omissão. Um estudo demonstrou que, em relação às produções do 'r-forte', a sílaba que mais sofreu casos de omissão foi a sílaba forte do pé métrico (ex.: rato) ${ }^{(18)}$. 
Tabela 3. Variáveis linguísticas não-selecionadas nas rodadas de Santa Maria e Crissiumal

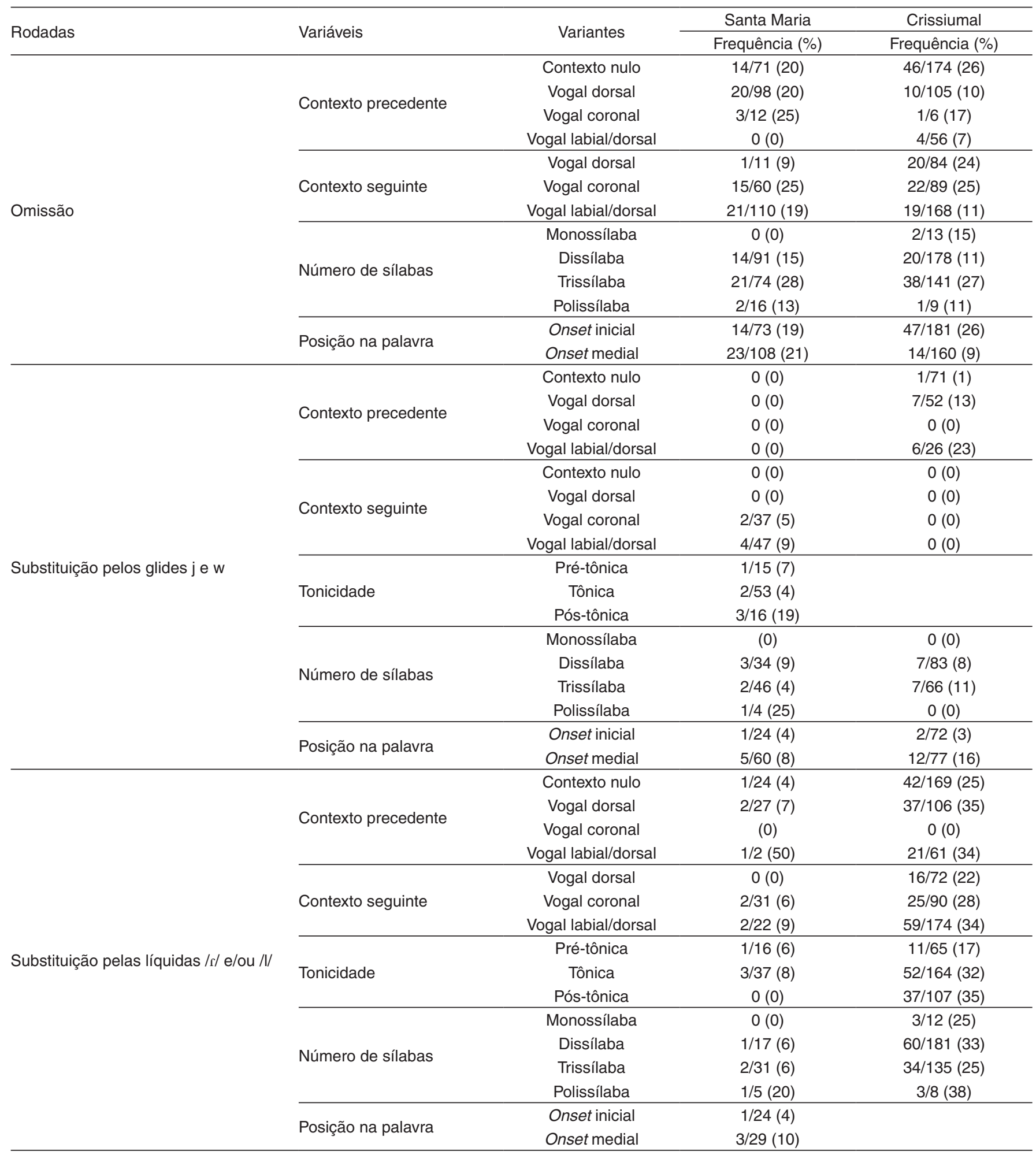

Pacote computacional VARBRUL $(\mathrm{p}<0,05)$

Em Crissiumal, na rodada da omissão, o programa estatístico selecionou as variáveis tonicidade (pré-tônica) e faixa etária. Um estudo que utilizou uma amostra de 36 sujeitos com desenvolvimento fonológico normal e 12 sujeitos com desvio fonológico evolutivo, a fim de descrever e analisar as estratégias de reparo utilizadas na posição de onset simples, também selecionou a variante pré-tônica (peso relativo 0,62) como favorecedora da omissão ${ }^{(19)}$. Em relação à faixa etária, pôde-se observar que a omissão ocorreu em faixas aleatórias em Crissiumal, o que indica a ocorrência do fenômeno chamado "curva em U". Esse fenômeno, quando colocado em um gráfico representado em percentagem no decorrer das idades, 
aparece como uma curva desenvolvimental em forma de $\mathrm{U}^{(5)}$. Isso significa que a aquisição ocorre de forma não-linear.

Na substituição pelo [j] e [w] em Santa Maria, a variável selecionada foi o gênero. Em Crissiumal, a variável selecionada nesta mesma estratégia foi a tonicidade, sendo a variante pós-tônica favorecedora desta estratégia. Um estudo que mostra os condicionadores para a semivocalização concluiu que a variante pós-tônica é a variante com a maior frequência de semivocalização ${ }^{(20)}$.

Em relação à substituição pela líquida lateral [1], em Santa Maria nenhuma variável foi selecionada. Porém, em Crissiumal, as variáveis selecionadas foram posição na palavra (onset medial), gênero (masculino) e faixa etária (faixas alternadas). Um estudo mostra que, dentre os processos fonológicos possíveis na aquisição fonológica, a substituição de líquida é o mais frequente, podendo estender-se até a idade pré-escolar ${ }^{(21)}$. Em outro estudo realizado com crianças de 1 ano e 6 meses a 2 anos e 6 meses, a líquida lateral surgiu nos dados de fala e foi empregada corretamente uma vez em onset medial quando a criança estava com 2 anos e 6 meses, mas não foi adquirida ${ }^{(9)}$. Dessa forma, o onset medial surgiu antes do onset inicial.

Em relação à variável gênero, ela foi selecionada duas vezes em Santa Maria (omissão e substituição por j e w) e uma vez em Crissiumal (substituição pela líquida lateral [1]). Nos casos mencionados, o gênero masculino sempre obteve maior frequência de uso das estratégias de reparo. Pode-se dizer que entre homens e mulheres, além das diferenças anatômicas externas, dos caracteres primários e secundários, a forma como eles adquirem o sistema linguístico, em particular a fonologia da sua língua, difere. Confirmando essa diferença, pode-se dizer que as meninas falam mais cedo e com menos erros gramaticais, sendo elas mais precoces na aquisição das habilidades linguísticas ${ }^{(22)}$.

Sobre a variável gênero, quando não selecionada pelo programa estatístico, (na omissão e na substituição por [j] e [w] em Crissiumal, e na substituição por [1] e [r] em Santa Maria), o gênero masculino somente não possuiu maior frequência de omissão em Crissiumal. Isso significa uma maior utilização de estratégias de reparo pelos meninos ${ }^{(22,23)}$, os quais adquirem os sons da fala mais tardiamente ${ }^{(24)}$. Essas informações são contrárias a um estudo que observou que as meninas apresentam mais erros do que os meninos ${ }^{(25)}$. Estes, segundo outro estudo, apresentam melhor desempenho em tarefas de consciência fonológica ${ }^{(26)}$. Há ainda estudos nos quais a variável gênero se mostrou neutra quanto à utilização de estratégias de reparo e quanto à ordem de aquisição de fonemas por sujeitos com desenvolvimento fonológico normal ${ }^{(1,27)}$ e sujeitos com distúrbios fonológicos ${ }^{(28)}$.

Em relação á variável extralinguística faixa etária, quando não selecionada, também apresentou decréscimos na produção, o que é normal durante a aquisição fonológica. Isso pode ocorrer porque a criança está aperfeiçoando uma habilidade, como o monitoramento do controle auditivo na fala para informações sinestésicas, a fim de que a criança crie estratégias mais eficazes para a produção correta dos sons da língua ${ }^{(9)}$.

Em relação à tonicidade, mesmo quando não selecionada pelo programa estatístico, houve uma prevalência da sílaba pós-tônica ter maior frequência para as estratégias de reparo. Um estudo mostra que existe um fenômeno chamado apagamento da sílaba átona, que ocorre geralmente em palavras de mais de uma sílaba (trissílabas ou polissílabas) ${ }^{(4)}$. Esse estudo confirma os achados da presente pesquisa, que relata que a omissão ocorre com maior frequência em palavras trissílabas e as estratégias de reparo, em geral, mesmo quando não selecionadas pelo programa estatístico, ocorrem em palavras trissílabas e polissílabas. Além disso, sílabas pós-tônicas são átonas. Seguindo esta ideia, outra pesquisa com crianças com desenvolvimento fonológico normal selecionou palavras trissílabas como favoráveis à semivocalização, confirmando os achados de Crissiumal (Tabela 4). A mesma pesquisa selecionou como favoráveis para a substituição de líquida as palavras polissílabas, confirmando os achados de Santa Maria e Crissiumal (Tabela 4). Outras variantes que foram observadas como favoráveis para a omissão nessa mesma pesquisa foram contexto vazio em contexto precedente, como em Crissiumal, e vogal labial em contexto seguinte, como em Santa Maria (Tabela 4) ${ }^{(19)}$

Portanto, através de uma análise geral das informações encontradas no presente estudo, pode-se afirmar que durante $\mathrm{o}$ processo de aquisição do $/ \mathrm{R} /$, as crianças expostas às diferentes variantes do fonema estudado fazem uso de diferentes estratégias de reparo. Em uma pesquisa sobre variação linguística e aquisição da linguagem ${ }^{(29)}$, os autores afirmam que é inegável que as crianças desenvolvem seu conhecimento fonológico, pelo menos parte dele, por meio da substância fonética à qual estão expostas. Os resultados desse estudo apontam que é necessário levar em consideração os padrões de variabilidade da comunidade adulta para uma avaliação precisa dos alvos que devem ser atingidos pela criança. Dessa forma, a criança precisa reproduzir corretamente as variantes sociolinguísticas apropriadas para a sua comunidade. Portanto, para que a variabilidade linguística não seja considerada um aprendizado imperfeito, deve-se descobrir qual o input recebido pela criança avaliada, antes de diagnosticar os casos de desenvolvimento fonológico atípico.

\section{CONCLUSÃO}

Foi possível observar que as estratégias de reparo podem divergir conforme a variante sociolinguística utilizada. Em Santa Maria, a estratégia de reparo mais utilizada foi a omissão, que se destacou em relação às outras. Em Crissiumal, a estratégia mais utilizada foi a substituição pela líquida lateral [1], seguida pela omissão. Além disso, pôde-se observar que as crianças em Crissiumal utilizaram mais estratégias de reparo durante as faixas etárias analisadas, pois, em Santa Maria, houve mais casos de produção correta.

A hipótese levantada neste estudo se confirma, ou seja, as estratégias de reparo empregadas pelas crianças expostas aos dois dialetos estudados são distintas. Portanto, as diferenças encontradas devem ser observadas para a análise de casos de desenvolvimento fonológico atípico.

Essa pesquisa justifica-se na medida em que poderá auxiliar os fonoaudiólogos no diagnóstico diferencial dos casos 
desviantes na aquisição e de variação dialetal, considerada desenvolvimento típico. Dessa forma, será evitado o tratamento desnecessário nos casos de variação linguística.

\section{REFERÊNCIAS}

1. Ferrante C, Borsel JV, Pereira MM. Aquisição fonológica de crianças de classe econômica alta. Rev CEFAC. 2008;10(4):452-60.

2. Lamprecht RR. Antes de mais Nada. In: Lamprecht, RR (Org.). Aquisição fonológica do Português: perfil de desenvolvimento e subsídios para terapia. Porto Alegre: Artmed; 2004. p.17-32.

3. Brescancini C, Monaretto VN. Os róticos no sul do Brasil: panorama e generalizações. Signum. 2008;11(2):51-66.

4. Othero GA. Processos fonológicos na aquisição da linguagem pela criança. ReVEL. 2005;3(5):1-13.

5. Miranda AR. A Aquisição do 'r': Uma contribuição à discussão sobre seu status fonológico [dissertação]. Porto Alegre: Faculdade de Letras da Pontifícia Universidade Católica do Rio Grande do Sul; 1996.

6. Vitor R, Cardoso-Martins C. Desenvolvimento fonológico de crianças pré-escolares da Região Noroeste de Belo Horizonte. Psicologia em Revista. 2007;13(2):383-98.

7. Costa LT. Estudo do rotacismo: variação entre as consoantes líquidas. [dissertação]. Porto Alegre: Programa de Pós-Graduação em Letras da Universidade Federal do Rio Grande do Sul; 2006.

8. Yavas M, Hernandorena CL, Lamprecht RR. Avaliação Fonológica da Criança. Porto Alegre: Artes Médicas; 1991.

9. Athayde ML, Baesso JS, Dias RF, Giacchini V, Mezzomo CL. O papel das variáveis extralinguísticas idade e gênero no desenvolvimento da coda silábica. Rev Soc Bras Fonoaudiol. 2009;14(3):293-9.

10. Moura SR, Mezzomo CL, Cielo CA. Estimulação em consciência fonêmica e seus efeitos em relação à variável gênero. Pró-Fono. 2009;21(1):51-6.

11. Cedergren HJ, Sankoff D. Variable rules: performance as a statistical reflection of competence. Language. 1974;50(2):333-55.

12. Scherre M. Introdução ao pacote VARBRUL para microcomputadores. Rio de Janeiro: UFRJ; 1993.

13. Garcia R, Zimmer M. O papel da frequência lexical e segmental na aquisição das fricativas em crianças de um a três anos: uma perspectiva dinâmica na aquisição do português brasileiro. Acta Sci Lang Cult. 2010;32(2):279-89.

14. Mezzomo CL, Mota HB, Dias RF, Giacchini V. Fatores relevantes para aquisição da coda lexical e morfológica no português brasileiro. Rev CEFAC. 2010;12(3):412-20.

15. Cruz GF. O processo de semivocalização das líquidas laterais em posição pré-vocálica: uma revisão teórica. Letrônica. 2009;2(2):48-57.
16. Ferrante C, Borsel JV, Pereira MM. Análise dos processos fonológicos em crianças com desenvolvimento fonológico normal. Rev Soc Bras Fonoaudiol. 2009;14(1):36-40.

17. Silva IM. Aquisição de líquida vibrante pós-vocálica em crianças de Bauru-SP e Brasília-DF. Revista do Centro de Ensino Superior Unificado de Brasília. 2004;1(2):123-37.

18. Oliveira CC. Aquisição das consoantes róticas no português brasileiro e no espanhol: um estudo comparativo [tese]. Porto Alegre: Faculdade de Letras da Pontifícia Universidade Católica do Rio Grande do Sul; 2006.

19. Ghisleni, MR. Estratégias de reparo em onset simples utilizadas por crianças com desenvolvimento fonológico normal e desviante [dissertação]. Santa Maria: Programa de Pós-Graduação em Distúrbios da Comunicação Humana da Universidade Federal de Santa Maria; 2009.

20. Ramos A. Semivocalização das líquidas e os possíveis condicionadores para sua ocorrência. In: V Mostra de Pesquisa de Pós-Graduação; 2010; Porto Alegre: Pontifícia Universidade Católica do Rio Grande do Sul.

21. Toreti G, Ribas LP. Aquisição fonológica: descrição longitudinal dos dados de fala de uma criança com desenvolvimento típico. Letrônica. 2010;1(3):42.

22. Sabbatini RM. Existem diferenças cerebrais entre os homens e as mulheres? Cérebro \& Mente.. [Internet]. [citado 2000 Dez 12]. Disponível em: www.cerebromente.org.br/n11/mente/eisntein/cerebrohomens-p.html

23. Patah LK, Takiuchi N. Prevalência das alterações fonológicas e uso dos processos fonológicos em escolares aos 7 anos. Rev CEFAC. 2008;10(2):158-67.

24. Queiroga BA, Alves JM, Cordeiro AA, Montenegro AC, Asfora R. Aquisição dos encontros consonantais por crianças falantes do Português não-padrão da região metropolitana do Recife. Rev CEFAC. 2010;13(2):214-26.

25. Mota HB, Athayde ML, Mezzomo CL. O acesso ao léxico em crianças com desenvolvimento fonológico normal e desviante. Letras de Hoje. 2008;43(3):54-60.

26. Andreazza-Balestrin C, Cielo CA, Lazzarotto C. Relação entre desempenho em consciência fonológica e a variável gênero: um estudo com crianças pré-escolares. Rev Soc Bras Fonoaudiol. 2008;13(2):15460.

27. Mezzomo CL, Mota HB, Dias RF, Giacchini V. O uso da estratégia de alongamento compensatório em crianças com desenvolvimento fonológico normal e desviante. Letras de Hoje. 2008;43(3):35-41.

28. Souza AP, Marques JM, Scott LC. Validação de itens para uma escala de avaliação da inteligibilidade de fala. Pró-Fono. 2010;22(3):325-32.

29. Docherty GP, Foulkes J, Tillotson D. The emergence of structured variation. Paper presented at the 3rd UKLVC. University of York. 2001. 